\title{
ARTIGO
}

\section{OS MUSEUS COMO ESPAÇOS EDUCATIVOS}

\author{
Maria da Graça J. Setton* \\ Universidade de São Paulo (USP), São Paulo - SP, Brasil \\ Mirtes Marins de Oliveira** \\ Universidade Anhembi Morumbi, São Paulo - SP, Brasil
}

RESUMO: O objetivo deste artigo é fazer uma reflexão acerca dos espaços museológicos como prática educativa. Concebendo-os como um lazer diferenciado, tem-se uma falsa representação de que parte da população seria incapaz de usufruir de seus acervos. Partindo de uma perspectiva histórica acerca dos museus e da teoria de Pierre Bourdieu, procurou-se observar estruturas mentais que instauram barreiras culturais para algumas linguagens e práticas. Nesse sentido, como inspiração, visitaram-se alguns acervos no intuito de apreender as estratégias de aproximação e/ou afastamento de suas exposições. Para finalizar, problematizando o envolvimento com práticas de cultura responsáveis em grande parte pela formação de um capital cultural, provocou-se a reflexão sobre as diferentes formas de apreciar e de se sensibilizar com artefatos culturais diversos.

Palavras-chave: Museus. Arbitrário cultural. Legitimidade cultural. Educação.

\section{MUSEUMS AS EDUCATIONAL SPACES}

ABSTRACT: The purpose of this article is thinking the Museum spaces as educational practice. Conceiving them as a differentiated leisure, one has a false representation of that part of the population would be unable to take advantage of your collections. Starting from a historical perspective about the museums and the theory of Pierre Bourdieu, we sought to observe mental structures that establish cultural barriers for some languages and practices. In this sense, as inspiration, we have visited some collections in order to seize the approximation strategies and/or removal of their exhibitions. Finally, the questioning of engagement with culture practices responsible in large part for the formation of a cultural capital has provoked a reflection on the different ways to enjoy and how become sensitize with various cultural artifacts.

Palavras-chave: Museums. Arbitrary culture. Cultural legitimacy. Education.

"Professora Titular de Sociologia pela Faculdade de Educação-USP. Coordenadora do GPS-Grupos Práticas de Socialização - FE-USP. E-mail: < gracaset@usp.br >.

"“Doutora em Educação: História, Política, Sociedade pela PUC-SP. Docente e pesquisadora do PPG Design da Universidade Anhembi Morumbi - Grupo de Pesquisa: Design de Exposições: Práticas em Arte, Moda e Fotografia (acesso para espelho: dgp.cnpq.br/dgp/espelhogrupo/7115284236836927). E-mail: <mirtescmoliveira@gmail.com >. 


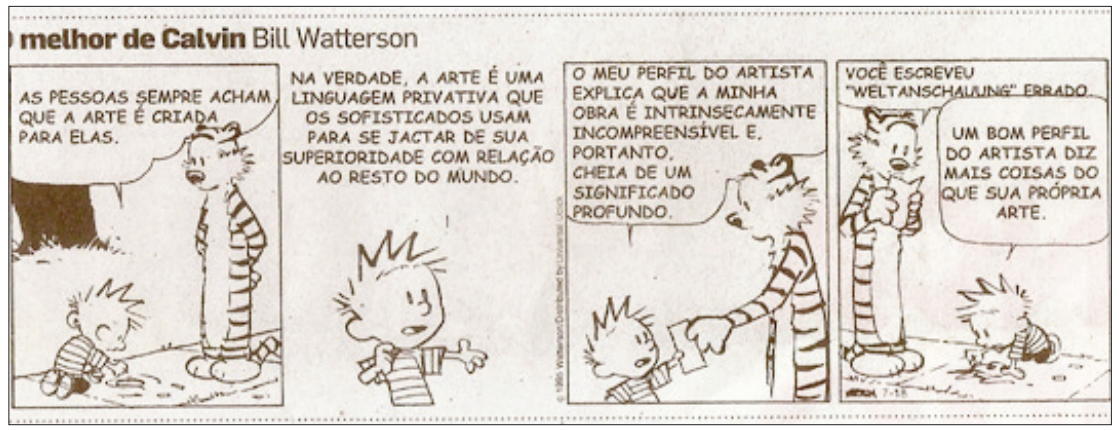

Fonte: 0 Estado de São Paulo, 2015

\section{INTRODUÇÃO}

A intenção de realizar essa discussão nasceu da visitação a dois museus da cidade de São Paulo - Museu de Arte de São Paulo Assis Chateaubriand (MASP) e Museu Afro Brasil ${ }^{1}$ - com duas turmas da disciplina Sociologia da Educação II, da Faculdade de Educação da USP, no segundo semestre de 2014. Tendo como objetivo demonstrar que em uma sociedade hierárquica e injusta como a brasileira podem desenvolver-se preconceitos e representações negativas acerca de aspectos da produção de cultura de alguns segmentos sociais, buscou-se identificar e analisar mecanismos objetivos e subjetivos dessa construção. Partindo de uma perspectiva histórica acerca dos museus e da teoria de Pierre Bourdieu, procurou-se observar estruturas mentais que instauram barreiras culturais para algumas linguagens e práticas. Nesse sentido, buscou-se visitar os acervos acima mencionados no intuito de apreender as estratégias de aproximação e/ou afastamento de suas exposições. Paralelo a isso, realizou-se uma visita aos estúdios da TV Cultura, em São Paulo, bem como teve-se a oportunidade de ir a uma peça teatral - Preto no Branco, do inglês Nick Gill, encenada no Sesc Bom Retiro, em São Paulo. Para finalizar o envolvimento com práticas de cultura responsáveis em grande parte pela formação de um capital cultural (BOURDIEU, 1979), provocou-se a reflexão sobre as diferentes formas de se apreciar e se sensibilizar com artefatos culturais diversos.

Como primeira síntese dessa empreitada pedagógica, foi-se desenvolvendo, entre os alunos, o entendimento de que havia uma falsa concepção de que estavam alheios a um código apreciativo diferenciado para a compreensão das obras expostas em museus e demais espaços visitados. Em todos eles, contudo, observou-se que necessitavam de um tipo de conhecimento prévio, disponibilizado em 
sala de aula, a fim de aproveitar com maior intensidade as múltiplas ideias ali propostas. Em especial em relação aos museus, ainda que os alunos estivessem cientes de sua pequena popularidade, simultaneamente, foi-se adquirindo uma percepção crítica acerca da crença de que essa prática era sagrada e ou reservada para privilegiados. Ao contrário, como qualquer forma de mídia, ${ }^{2}$ ela poderia e deveria estar entre o leque de atividades culturais e de lazer de todos, sem diferença de origem, desde que condições de socialização assim o permitissem.

Vale lembrar a recepção que tivemos no Museu Afro Brasil. Sendo o dia da Consciência Negra, uma banda de músicos angolanos fazia uma performance. Fomos convidados para dançar e cantar juntos, o que nos pareceu uma estratégia aproximativa bastante original. Por outro lado, ao entrar na exposição, certo estranhamento se instaurou no grupo. Peças de origem diversa, de beleza incomum eram apresentadas sem nenhum tipo de explicação. Essa questão permeou todo nosso trajeto por lá. Na visitação ao MASP, a impressão que tivemos foi um pouco diferente. Logo na entrada, nos encaminhamos para uma exposição acerca da Arte Iorubá. Objetos ritualísticos, de caráter religioso e social, estavam em vitrines fechadas, em um ambiente escuro, como se fossem joias sagradas. Dando continuidade à visita, fomos surpreendidos com um conjunto de obras conhecidas e reconhecidas, sendo a ênfase dada à produção europeia do Impressionismo. Mais uma vez, constatávamos a falta de um encaminhamento no trajeto e certa explicação sobre a importância histórica e artística de cada uma delas.

\section{JUSTIFICATIVA}

Num esforço de mapear algumas estratégias objetivas que dificultam a aproximação de grandes públicos com os museus, uma incursão na história dessas instituições torna-se pertinente. Parte-se do pressuposto de que os museus, enquanto espaços educativos e socializadores, cumprem a função subliminar de transmitir, a partir de sua história e arquitetura, da apresentação de obras, seleção de acervo, entre outros aspectos, um conjunto de símbolos que prestigiam seus objetos, que, por vezes, reificam a natureza sacralizada das peças de sua exposição. Em outras palavras, uma atenta leitura sobre os programas educativos em museus de arte ou de ciência nos mostra uma tensão contínua. Ainda que a proposta educativa ou mesmo o desejo e a preocupação dessa dimensão sejam uma constante nos 
depoimentos de seus administradores, não se consegue registrar uma tradição na área. Apenas a partir dos anos de 1980, o debate se ampliou graças ao incremento de contatos com as escolas de Ensino Fundamental e Médio (BARBOSA, 2009). Se conflitos entre curadorias e educativos nos museus parecem ser uma realidade de longa data, atualmente, pelo que se convencionou chamar de Virada Educacional na Curadoria e na Produção Artística (O’NEILL; WILSON, 2010), observamos novas apropriações de temáticas, processos, métodos e debates. Enfim, outro desenho do campo educacional, por parte de artistas e curadores ${ }^{3}$ (MÖRSCH, 2011). Não obstante, historicamente, as curadorias - em especial aquelas organizadas em museus - tendem a enfocar a produção artística, a difusão das obras dos acervos e ou exposições isoladamente, sendo o processo educacional, invariavelmente, setorizado na divisão de trabalho das instituições. ${ }^{4}$ Mesmo nos museus mais antigos e com empenho em divulgar coleções científicas, tais como o Victoria and Albert Museum, na Inglaterra, o enfrentamento entre setores educativos e curatorial, a cada exposição, é uma realidade sobre a qual se debruçar (MARANDINO, 2008; MACMANUS, 2013).

Cumpre lembrar que os museus de ciências e de artes surgiram no panorama cultural internacional à medida que países como Inglaterra, França e Espanha, entre outros, se ocupavam em colonizar amplas regiões do novo mundo. Com viagens exploratórias e de conhecimento, as expedições eram compostas por profissionais de várias áreas disciplinares que, imbuídos da tarefa de compreender o novo mundo, desenhavam e coletavam objetos e artefatos diversos. Em campos tão distintos como biologia e religião, por exemplo, os responsáveis por essas viagens trouxeram, muitas vezes na forma de pilhagem, um conjunto de materiais que aos poucos foram sendo armazenados em grandes coleções nacionais. Era uma forma de trazer à tona o poderio dos governos europeus, bem como uma estratégia subliminar de fragilizar e tornar exóticos vários dos territórios conquistados. Se a intenção inicial era apresentar o material coletado apenas para alguns privilegiados, somente em 1870, na Inglaterra, foi permitida a entrada do público nos museus. Só teriam acesso aqueles que estivessem bem vestidos e não cheirassem mal, pois ali era um lugar especial (MACMANUS, 2013, p. 13).

Com certo espanto e desconfiança, lemos as histórias relatadas pelos estudiosos dos educativos em museus. Parece ser uma tarefa árdua e por vezes inglória tentar articular dois setores envolvidos, isto é, a curadoria e os outros setores de difusão. Somada a essa tensão, 
devemos lembrar ainda da participação fugaz de mais um agente, a escola, notadamente seus professores. Por certo, não devemos cobrar dos museus a tarefa de uma educação formal e sistemática. Contudo, o que caracterizaria a educação museológica seria sua capacidade de apresentar, a partir de estímulos diversos, uma realidade de cultura diferente daquela a que temos acesso cotidianamente.

À primeira vista, não nos parece impossível a tarefa. Ela serviria para desmistificar os museus como locais e espaços consagrados para poucos privilegiados. Todavia, medidas até certo ponto consensuais são muito difíceis de serem alcançadas. Iniciativas de longo prazo não parecem fazer parte das instituições museológicas. Basta lembrar que o MASP, o maior e o mais reconhecido entre os museus brasileiros, convive com crises financeiras constantes. Seus administradores mal conseguem manter e conservar o acervo. ${ }^{5}$ Como pensar em algo mais inovador do ponto de vista da democratização daquele patrimônio? Tudo leva a crer que ações dessa natureza exigiriam uma política pública mais diretiva e assertiva. Por ora, ainda que se diga o contrário, os museus continuam sendo um lazer ou um negócio para pequenos grupos de estudiosos e amantes da arte, e a sensação de que eles estão distantes do nosso olhar corrobora objetivamente o mito e o fetiche de que eles são destinados para poucos. Vejamos alguns exemplos.

\section{A EXPERIÊNCIA DO MODERN MUSEUM OF ART, EM NOVA YORK, E DO MUSEU DE ARTE DE SÃO PAULO ASSIS CHATEAUBRIAND, EM SÃO PAULO}

A escolha de fazer um pequeno histórico do processo de criação do Modern Museum of Art (MoMA) e do Museu de Arte de São Paulo Assis Chateaubriand (MASP) responde aos propósitos de sinalizar aspectos objetivos que fundamentam sua interação restrita com o público. Ou seja, trata-se de um exercício de apresentar a origem e os interesses que mobilizaram e mobilizam os artífices de empreendimentos dessa natureza. Fundado em 1929, na cidade de Nova York, por iniciativa de três representantes de famílias de empresários locais, o MoMA logrou ser um espaço de conservação, divulgação e difusão de uma produção artística moderna e contemporânea (BIRKET'T, 2012). Idealizado por Lilie P. Bliss, Abby Aldrich Rockefeller e Mary Quinn Sullivan com o objetivo de divulgar a arte realizada naquele momento, o museu foi dirigido por Alfred Barr Jr. (1902-1981), que determinou suas diretrizes curatoriais. O MoMA se destacou e serviu de modelo para empreendimentos semelhantes em várias partes do mundo, como componente da 
política de propagação da cultura norte-americana no contexto da Guerra Fria, em especial pela atuação do empresário e político Nelson Rockefeller (1908-1979), filho de uma das fundadoras e um dos administradores do museu. ${ }^{6}$

A história nos conta a importância desse modelo no Brasil (TOTA, 2014). Ou seja, tal ascendência do museu norte-americano sobre os agentes culturais brasileiros sugere um olhar para as estratégias que lá se desenvolveram. Aqui nos interessa dar destaque à proposta educativa, que é premissa do MoMA, que em realidade se apresentava como um elaborado plano de divulgação de sua coleção e do american way of life. Vale salientar, entre outros aspectos, a pluralidade de formas de difusão de seu acervo a partir de cartilhas didáticas e explicativas, material pedagógico para professores, catálogos, exposições itinerantes que contemplavam o ambiente urbano e industrial (STANISZEWSKI, 1998). Por outro lado, muitas são as exposições que enfatizaram objetos de consumo descontextualizados de suas origens produtivas ou mesmo de seu contexto de utilização, como o exemplo da famosa mostra Machine Art (1934). Ressaltando uma estética idealista, exibiu partes de maquinarias e outros elementos industriais escolhidos a partir da categoria beleza, aqui compreendida da perspectiva do projeto moderno advindo da Bauhaus: ausência de adornos; a forma seguindo a função; preponderância de elementos geométricos ${ }^{7}$ (STANISZEWSKI, 1998). Do ponto de vista institucional, Alfred Barr Jr., durante sua gestão (1929-1943), implementa uma política multidepartamental que amplia a noção de arte moderna e, ao mesmo tempo, de museu de arte. Em 1932, inaugura a biblioteca do museu e, em 1935, a Film Library, um tipo de departamento/serviço inédito naquela época, composto por doações e aquisições a partir do acervo dos artistas hollywoodianos, entre outros, D. W. Griffith e Douglas Fairbanks (BIRKETT, 2012).

Em 1937, é inaugurado o projeto educacional do MoMA, com o convite feito por Barr para Victor D'Amico. O museu passa a ter uma escola na qual futuros diretores foram alunos: Artur Drexler (departamento de Arquitetura e Design) e Willian Rubin (Pintura e Escultura). O projeto educacional incluía programas de apreciação artística para jovens e mesmo exposições e atividades voltadas exclusivamente para crianças, alinhando-se, assim, com um interesse sobre a dimensão educacional dos museus, típico dos anos de 1930 e 1940, nos Estados Unidos (STANISZEWSKI, 1998). Com a aposentadoria de D'Amico, em 1970, as atividades da escola foram encerradas (HUNTER, 1997). 
Entusiasmados com a novidade curatorial e museológica dos Estados Unidos, setores da elite cultural brasileira sentiramse motivados para adotar, em solo paulista, iniciativa de natureza semelhante, em virtude do sucesso em reconhecimento e visibilidade no campo cultural obtida pelos empresários envolvidos. É necessário lembrar que essa mobilização local foi contemplada pelo esforço governamental norte-americano para divulgação do modus operandi e produções daquele país, no árido ambiente cultural do Pós-guerra. Foi o caso específico do MASP. O Museu de Arte de São Paulo Assis Chateaubriand foi produto de um feixe de condições históricas que articulou crescimento econômico, a emergência de grupos responsáveis pelos avanços industrial e financeiro e o nascimento de profissionais que agregaram expertises de naturezas diversas. No caso específico aqui tratado, a criação do MASP evidenciou a consolidação de alianças entre uma elite econômica e cultural, protagonizando um movimento hegemônico nessa parte da produção/reprodução da cultura no Brasil.

Aproveitando as condições de um contexto específico, parte da elite brasileira, capitaneada por Assis Chateaubriand, revelou-se fortemente atenta aos destinos de obras de arte em um momento em que a Europa estava se recompondo da II Guerra Mundial. $\mathrm{Na}$ procura de um empreendimento simbolicamente reconhecido, frações daquele grupo, com apoio de um crítico e jornalista italiano, Pietro Maria Bardi, não se ocuparam apenas do investimento na indústria de transformação nos limites urbanos. Parte dela investiu notadamente em acumular prestígio e refinamento cultural apoiando iniciativas de compra e montagem de um dos acervos mais famosos do mundo das artes na América Latina.

A discussão sobre a necessidade de divulgação da arte moderna (TOTA, 2014, p. 344) é pauta para os artistas e os críticos envolvidos com aquela produção durante o ano de 1946. Ao final daquele mesmo ano, Nelson Rockefeller chega ao Brasil em sua terceira visita, dessa vez não apenas para tratar de negócios e parcerias entre Estados Unidos e Brasil, mas com projetos para o campo cultural. Para isso, traz quase 200 quilos de obras de arte que seriam distribuídas entre os museus brasileiros, para os quais o empresário e político prestava aconselhamento (TOTA, 2014). No Brasil, entre outros países, encontrou Assis Chateaubriand, o então financiador envolvido com a fundação do MASP, que se daria no ano seguinte. Apesar das boas relações entre Rockefeller, como representante do MoMA, Chateaubriand e Pietro Maria Bardi, diretor do museu, o 
MASP não se enquadrou nos propósitos de Rockefeller, já que o forte de sua coleção eram as aquisições de obras clássicas europeias.

O MASP, desde seu nascimento, em 1947, e após sua mudança para uma das construções ícone da arquitetura paulista, o edifício de Lina Bo Bardi (1968) ${ }^{8}$ na Avenida Paulista, destaca-se entre os museus mais visitados e prestigiados de São Paulo. Com acervo altamente reconhecido pelos experts de uma arte tradicional, com quase oito mil objetos de consensual valor, continua sendo de propriedade privada, mas com apoio de setores representativos da elite paulistana e brasileira e do setor público. Seu conselho diretor segue sendo proveniente das famílias mais tradicionais do Brasil e o trabalho de sua nova direção curatorial aposta em retraduzir um patrimônio cultural em uma variedade de exposições anuais. Ainda que o MASP tenha nascido sob a perspectiva de um museu educativo, se considerarmos as concepções sobre museus de Lina Bo Bardi ${ }^{9}$ e, sobretudo, conserve em seu material publicitário essa dimensão, não se consagrou com esse modelo. ${ }^{10}$ Seria preciso olhar para empreendimentos mais sistemáticos e com comprometimentos mais pedagógicos como os desenvolvidos pelo Museu de Arte Contemporânea de São Paulo, por exemplo.

Por fim, ainda entre as estratégias de ordem objetiva que distanciam os museus de um público de massa, destaca-se aqui a forma de gestão dos museus de arte. Até hoje, a grande maioria deles é apoiada administrativamente e mantida por grandes empresas. Por exemplo, o MAM-SP tem como seus mantenedores bancos como Bradesco, Itaú, Votorantin e as empresas Gerdau, Samsung e Telefônica Vivo. Nessa linha de raciocínio, o conselho deliberativo do MASP - composto por 83 membros, grande parte deles empresários do comércio (Riachuelo) e investimentos financeiros - tem entre seus diretores estatutários figuras ligadas a altos postos do Itaú BBA, Embraer, Credit Suisse, entre outras empresas brasileiras e estrangeiras. A condução de seus propósitos, pedagógicos ou não, ainda que tenha parceria com órgãos públicos e ou educativos, não possui uma sistemática contínua. Como se pode verificar no quadro abaixo $^{11}$, os museus analisados sinalizam atividades educativas grátis, visitas guiadas, ateliês, cursos de arte, entre outros, na tentativa de aproximar um público mais cativo. Contudo, devido à sua pequena visibilidade e efetividade, acabam acessando uma reduzida audiência. 
QUADRO 1 - Museus de Artes - São Paulo

\begin{tabular}{|c|c|c|c|}
\hline $\begin{array}{c}\text { Museus } \\
\text { (dados atualizados } \\
\text { em set/16 a partir } \\
\text { de informações } \\
\text { oferecidas pelos } \\
\text { websites das } \\
\text { instituições) }\end{array}$ & $\begin{array}{c}\text { Histórico e } \\
\text { características }\end{array}$ & Atividades educativas gratuitas & $\begin{array}{c}\text { Atividades } \\
\text { educativas } \\
\text { pagas }\end{array}$ \\
\hline $\begin{array}{l}\text { Museu de Arte de } \\
\text { São Paulo "Assis } \\
\text { Chateaubriand" } \\
\text { MASP } \\
\text { http://masp.art.br/ } \\
\text { masp2010/ }\end{array}$ & $\begin{array}{l}\text { Museu privado sem fins } \\
\text { lucrativos, fundado pelo } \\
\text { empresário brasileiro } \\
\text { Assis Chateaubriand, em } \\
\text { 1947. Acervo de } 8.000 \\
\text { peças, em sua grande } \\
\text { maioria de arte ocidental, } \\
\text { desde o século IV a.C. } \\
\text { aos dias de hoje. }\end{array}$ & $\begin{array}{l}\text { - Masp Palestras sobre tópicos da coleção } \\
\text { - Masp Oficinas sobre tópicos das exposições } \\
\text { - Masp Seminários sobre tópicos de interesse } \\
\text { curatorial do Museu (1 por semestre) } \\
\text { - O Masp não oferece visitas guiadas, mas } \\
\text { apoia professores interessados em fazê-las. }\end{array}$ & Masp Cursos \\
\hline $\begin{array}{l}\text { Museu de Arte } \\
\text { Moderna - São } \\
\text { Paulo } \\
\text { MAM-SP } \\
\text { http://mam.org.br/ }\end{array}$ & $\begin{array}{l}\text { Sociedade civil de } \\
\text { interesse público, sem } \\
\text { fins lucrativos, fundada } \\
\text { em } 1948 \text {. } \\
\text { Possui cerca de } 5.000 \\
\text { obras de arte moderna e } \\
\text { contemporânea. }\end{array}$ & $\begin{array}{l}\text { - Visitas guiadas, mediante agendamento, com } \\
25 \text { pessoas. } \\
\text { - Eventos voltados para famílias. } \\
\text { - Eventos dominicais. } \\
\text { - Contatos com a Arte: atividades de formação } \\
\text { para professores e educadores. } \\
\text { - Cursos (Oficinas) } \\
\text { - Escolas Parceiras: parceria envolvendo apoio } \\
\text { conteudístico e visitas. Voltado à escolas } \\
\text { públicas e privadas. } \\
\text { - Projeto Olhar de Perto: voltado para } \\
\text { deficientes visuais e interessados. Oferece } \\
\text { cursos, galeria tátil e audio guia. }\end{array}$ & Cursos \\
\hline $\begin{array}{l}\text { Museu de Arte } \\
\text { Contemporânea } \\
\text { da Universidade } \\
\text { de São Paulo } \\
\text { MAC-USP } \\
\text { http://www. } \\
\text { mac.usp.br/mac/ } \\
\text { index.asp }\end{array}$ & $\begin{array}{l}\text { O Museu de Arte } \\
\text { Contemporânea foi } \\
\text { criado em } 1963 \text { quando } \\
\text { a Universidade de } \\
\text { São Paulo recebeu } \\
\text { o acervo do antigo } \\
\text { MAM de São Paulo, } \\
\text { formado pelas coleções } \\
\text { do casal de mecenas } \\
\text { Yolanda Penteado e } \\
\text { Ciccillo Matarazzo, } \\
\text { pelas coleções de obras } \\
\text { adquiridas ou recebidas } \\
\text { em doação durante a } \\
\text { vigência do antigo MAM } \\
\text { e pelos prêmios das } \\
\text { Bienais de São Paulo, } \\
\text { até } 1961 \text {. }\end{array}$ & $\begin{array}{l}\text { - Acervo: Roteiros de Visita. Material com } \\
\text { conteúdos sobre o acervo. Distribuído online. } \\
\text { - Histórias da Arte para crianças: encontros } \\
\text { entre livros e obras - relações entre obras de } \\
\text { artistas contemporâneos brasileiros presentes } \\
\text { no acervo do MAC e livros sobre artistas. } \\
\text { - Interarte Famílias no Museu. } \\
\text { - Lazer para 3a idade. } \\
\text { - Museu, Educação e Lúdico: produção } \\
\text { e disseminação de jogos sobre obras } \\
\text { e exposições. Parcerias com escolas e } \\
\text { preparação de professores. } \\
\text { - Poéticas Visuais em interação: Ateliês para } \\
\text { jovens artistas e educadores. } \\
\text { - Ver e Ler: projetos voltados para alunos } \\
\text { adultos em processo de alfabetização. } \\
\text { - Inclusão Socioeducativa e Cultural Viva } \\
\text { Arte! - programa para jovens em situação de } \\
\text { vulnerabilidade. } \\
\text { - Cursos }\end{array}$ & Cursos \\
\hline
\end{tabular}




\begin{tabular}{|c|c|c|c|}
\hline $\begin{array}{c}\text { Museus } \\
\text { (dados atualizados } \\
\text { em set/16 a partir } \\
\text { de informaç̃̃es } \\
\text { oferecidas pelos } \\
\text { websites das } \\
\text { instituições) }\end{array}$ & $\begin{array}{c}\text { Histórico e } \\
\text { características }\end{array}$ & Atividades educativas gratuitas & $\begin{array}{c}\text { Atividades } \\
\text { educativas } \\
\text { pagas }\end{array}$ \\
\hline $\begin{array}{l}\text { Pinacoteca do } \\
\text { Estado de São } \\
\text { Paulo } \\
\text { http://www. } \\
\text { pinacoteca.org. } \\
\text { br/pinacoteca-pt/ }\end{array}$ & $\begin{array}{l}\text { A Pinacoteca do Estado } \\
\text { de São Paulo é um } \\
\text { museu com ênfase na } \\
\text { produção brasileira desde } \\
\text { o século XIX. Fundada } \\
\text { em } 1905 \text { pelo Governo } \\
\text { do Estado de São Paulo } \\
\text { é o museu de arte mais } \\
\text { antigo da cidade. Desde } \\
\text { 2006, a Pinacoteca é } \\
\text { administrada pela APAC } \\
\text { - Associação Pinacoteca } \\
\text { Arte e Cultura. Criada em } \\
\text { 1992, é uma sociedade } \\
\text { civil de direito privado, } \\
\text { sem fins lucrativos. } \\
\text { Qualificada no final de } \\
2005 \text { como Organização } \\
\text { Social de Cultura. } \\
\text { Subordinada à Secretaria } \\
\text { de Cultura do Estado de } \\
\text { São Paulo. }\end{array}$ & $\begin{array}{l}\text { - Consciência Funcional: programa aos } \\
\text { profissionais do atendimento ao público } \\
\text { (atendentes e recepcionistas), à equipe de } \\
\text { manutenção e aos prestadores de serviço } \\
\text { (equipes de segurança e limpeza). } \\
\text { - Meu Museu: projeto de visitas de grupo de } \\
\text { idosos. Parceria com instituições. } \\
\text { - Museus para todos: material de estudo } \\
\text { disponível online. } \\
\text { - Pina Família: visitas para famílias. } \\
\text { - Programa de Inclusão Sociocultural, em } \\
\text { parceria com instituições. } \\
\text { - Programa Educativo para Públicos Especiais. } \\
\text { Para atendimento de deficientes. } \\
\text { - Visitas Guiadas espontâneas e agendadas. }\end{array}$ & $\begin{array}{l}\text { Curso de } \\
\text { História da } \\
\text { Arte }\end{array}$ \\
\hline $\begin{array}{l}\text { Museu Afro } \\
\text { Brasil } \\
\text { http://www. } \\
\text { museuafrobrasil. } \\
\text { org.br }\end{array}$ & $\begin{array}{l}\text { Instituição pública, } \\
\text { subordinada à Secretaria } \\
\text { da Cultura do Estado de } \\
\text { São Paulo e administrado } \\
\text { pela Associação Museu } \\
\text { Afro Brasil - Organização } \\
\text { Social de Cultura. } \\
\text { Acervo com mais de } \\
6.000 \text { obras, entre } \\
\text { pinturas, esculturas, } \\
\text { gravuras, fotografias, } \\
\text { documentos e peças } \\
\text { etnológicas, de autores } \\
\text { brasileiros e estrangeiros, } \\
\text { produzidos entre o século } \\
\text { XVIII e os dias de hoje. } 0 \\
\text { acervo abarca diversos } \\
\text { aspectos dos universos } \\
\text { culturais africanos e afro- } \\
\text { brasileiros }\end{array}$ & $\begin{array}{l}\text { - Museu promove visitas guiadas agendadas } \\
\text { e temáticas. } \\
\text { - Programa de Acessibilidade Singular Plural. } \\
\text { Atendimento de pessoas com deficiências } \\
\text { múltiplas (visitas, oficinas, palestras, eventos } \\
\text { e materiais de apoio) } \\
\text { - Programa de Formação de Professores: } \\
\text { voltado para professores e gestores de escolas } \\
\text { públicas e privadas. } \\
\text { - Programa de Formação e Atendimento a } \\
\text { Organizações Sociais: voltado para história, } \\
\text { memória e arte da perspectiva do negro. } \\
\text { - Oficinas e eventos variados. }\end{array}$ & \\
\hline
\end{tabular}

Fonte: Elaborado pelos autores.

Ainda que existam esforços dos órgãos governamentais para viabilizar o acesso para grupos de estudantes de escolas públicas visitarem os aparelhos culturais da cidade - fornecendo preparação 
de professores, atendimento na instituição e transporte -, na prática, essas ações, por questões de custo, não conseguem atender a todos os alunos. É recorrente o relato de professores de arte de escolas públicas que, depois de um semestre trabalhando com todas as salas sob sua responsabilidade a partir de determinados conteúdos relacionados à visitação, devem escolher apenas uma delas para conhecer o museu, devido à oferta restrita de transporte (SABOR, 2014).

\section{O MUSEU DE ARTE CONTEMPORÂNEA DE SÃO PAULOE E GESTÃO DE ANA MAE BARBOSA}

$\mathrm{Na}$ tentativa de fazer um levantamento sobre as iniciativas educativas em museus, o nome de Ana Mae Barbosa surge como um marco divisório na história do ensino e da divulgação da arte no Brasil. A gestão de Ana Mae Barbosa no Museu de Arte Contemporânea da USP (MAC-USP), durante os anos 1987 e 1993, foi determinante para a disseminação de suas propostas educacionais e para a instauração quase definitiva da inter-relação entre práticas de sala de aula e o interior dos museus. Durante o período, ocupou a presidência da International Society of Education through Art (InSea) - 1990 e 1993 - e, em 1991, lançou o livro A imagem no Ensino da Arte, no qual foram explicitados os princípios do que era então denominado pela autora como "Metodologia triangular" (BARBOSA, 2009).

O livro A imagem no Ensino da Arte, além de mostrar detalhes das práticas de trabalho do setor educativo do Museu, enfatizadas sob a gestão de Barbosa, buscava evidenciar os conteúdos que compunham a disciplina Arte, certamente como forma de combater as concepções que dominaram os documentos regulares do ensino artístico durante os anos de 1970 (BARBOSA, 2009). Até então, esses materiais consideravam a área não como uma disciplina, mas como uma atividade. Para isso, Ana Mae Barbosa recorreu a análises de livros de ensino de arte publicados fora do Brasil e demonstrativos de metodologias utilizadas em salas de aula (OLIVEIRA, 2010).

Além dessas ações, naquele período, Barbosa concebeu um evento de dimensão internacional, em 1989, o III Simpósio Internacional de Ensino da Arte e sua História, sediado no Museu de Arte Contemporânea da Universidade de São Paulo (BARBOSA; SALES, 1990). Nesse simpósio, diante de especialistas internacionais, as pesquisas sobre a "Metodologia triangular" foram apresentadas e tornaram-se fundamento incontornável na formação de professores de arte desde então.

A "Metodologia triangular" foi, posteriormente, revisada pela própria autora ${ }^{12}$ que, considerando um equívoco a denominação 
metodologia, rebatizou-a como Abordagem triangular ou Proposta triangular (BARBOSA; CUNHA, 2010). O triângulo, nesse caso, referia-se às três ações que pautariam o trabalho de ensino e aprendizagem em sala de aula, mas também, no caso do MAC, como processo educacional desenvolvido pelos educadores do museu. Seriam eles: a) a contextualização da obra; b) o fazer artístico e c) a leitura da obra de arte. De forma clara, essas ações buscavam romper a compreensão e a prática da arte em sala de aula como uma atividade sem contexto histórico, e, na qual, o ato de analisar e interpretar as obras seriam vistos como uma agressão à pureza expressiva na qual crianças e adolescentes viveriam (OLIVEIRA, 2010).

Do ponto de vista da própria autora, a abordagem foi sistematizada - e não criada - em consonância com várias outras também organizadas e disseminadas durante os anos de 1970 e 1980, marcadas pelas teorias pós-modernas. Entre elas Barbosa indica os Critical Studies (Inglaterra) e o DBAE - Disciplined Based Art Education (Estados Unidos). Critical Studies e a Abordagem triangular incorporam em sua proposta uma ampliação do campo de conteúdos no ensino de arte, ao utilizar a produção do design e da propaganda como constituintes daquele campo. A justificativa, no caso de Barbosa, era de caráter profissional e estratégico, já que considerava que uma boa formação em arte desde a infância iria resultar em profissionais capacitados no futuro, atuantes em uma economia que se pauta pelo uso intenso da imagem: televisão, cinema, internet, design, artesanato, arte, entre outros. Além dessa premissa, Barbosa indica outra, de caráter mais político: a mesma incorporação da imagem produzida fora do âmbito artístico em sala de aula permitiria uma espécie de desconstrução do discurso dominante - a arte europeia ou norte-americana-, já que, ao lado dessas produções hegemônicas, seriam analisadas outras, a da cultura popular, por exemplo (BARBOSA, 2009).

Já o DBAE (Discipline-Based Art Education) - cujos elaboradores do ponto de vista teórico foram Manual Barkan e Elliot Eisner, ainda durante os anos de 1960, nos Estados Unidos - compreende o conteúdo da arte como uma articulação de temas de quatro disciplinas inter-relacionadas: História da Arte, Crítica de Arte, Estética e Produção Artística. Esse movimento pós-moderno no ensino de arte trazia, portanto, a produção artística do circuito para dentro da sala de aula, ignorando possíveis interferências negativas nos processos de criação dos alunos, pelo contrário, considerando-os como positivas. Nesse movimento, nada mais compreensível do que 
a incorporação do museu como lócus privilegiado desse ensino, de atividade extracurricular. Dessa maneira, a visitação a museus passa a ocupar o lugar central da proposta (BARBOSA, 2009).

$\mathrm{Na}$ realidade, o projeto de Barbosa não era direcionado em especial ao ensino de arte em um museu. Como gestora de um museu relevante - de grande porte, com coleção significativa do ponto de vista histórico, voltado para a pesquisa, na mais consolidada, respeitada e poderosa universidade da América Latina-, a autora buscou proporcionar o máximo em termos de formação aos professores das escolas públicas e privadas a partir dessa abordagem. Sua gestão estimulou contato dos professores brasileiros com vários pesquisadores internacionais, que sistematizaram, naquele período, outras tantas abordagens para o ensino de arte ou que faziam sua crítica. A ênfase nos processos de leitura da obra de arte também ampliou conteúdos teóricos no âmbito da formação daqueles professores (OLIVEIRA, 2010).

A própria Ana Mae Barbosa, em Imagem no Ensino da Arte, aponta para um movimento paralelo. Mais especificamente, estava em curso uma mobilização profissional e política da classe de professores de arte que encontra seu ápice nas atividades das associações de arte-educadores, estaduais e federal. Essa mobilização serviu para o fortalecimento, a consolidação e as garantias da obrigatoriedade do ensino da arte nos diferentes níveis de ensino (BARBOSA, 2009).

Em meio à gestão de Ana Mae Barbosa, os professores do MAC criaram práticas que se disseminaram em outros museus e em exposições temporárias de dimensões variadas, como exemplo, a Bienal de São Paulo. Passou-se a propor a leitura da obra de arte presencialmente. Essa leitura era realizada de forma dialogada, utilizando teorias variadas, como a semiótica, por exemplo. Logo nesse primeiro instante, a visita prosseguia nos ateliês do museu, onde desde informações históricas sobre um trabalho específico até oficinas de arte poderiam ser parte do aprendizado. Essa sequência não era fixa, poderia ser invertida. Nesses processos, muitas vezes exercícios de releitura da obra de arte podiam ser desenvolvidos: entre outros, a elaboração de artefatos nos quais referências do trabalho lido no espaço expositivo novamente apareciam (OLIVEIRA, 2010).

Durante todo o período de gestão de Barbosa no MAC, além dos eventos internacionais - simpósio e professores estrangeiros convidados -, a equipe de educadores do Museu trabalhou ativamente no apoio aos professores de escolas públicas e privadas, na preparação das visitas e ministrando cursos da perspectiva da Abordagem triangular. Contudo, após sua saída da administração 
do museu, essas iniciativas foram se esmaecendo até que se dissolveram em fragmentos particulares e específicos nas práticas institucionais. Infelizmente, apesar de seu sucesso, não lograram uma política educativa sistemática, mas foram incorporadas formal ou informalmente nas escolas públicas e privadas ${ }^{13}$. Talvez por sua simbologia histórica, a Abordagem triangular serviu para forjar uma identidade do professor da área, o que pode ter adiado uma revisão crítica de seus pressupostos e desenvolvimento.

Parte desse sucesso pode ser verificado na incorporação dos aspectos contextuais (em maior ou menor grau) nas práticas educativas dos museus de arte da cidade de São Paulo, por exemplo: a oferta de eventos sistemáticos para segmentos específicos do público frequentador, como idosos, famílias, pessoas portadoras de necessidades especiais, crianças; práticas formativas voltadas para educadores; a incorporação de que parte da missão do museu é educacional, com a oferta específica de cursos nas áreas de ação da instituição. Em alguns casos, como o MAC/USP, a Pinacoteca e o Museu Afro Brasil, os materiais educacionais são disponibilizados pela rede digital para facilitar as visitas e permitir o aprofundamento de informações sobre arte, cultura e educação ${ }^{14}$.

\section{OS MUSEUS E 0 PÚBLICO}

Com a expectativa de apresentar as estratégias subjetivas de distanciamento dos museus de um público mais amplo, valeria circunstanciar brevemente o debate acerca da teoria da legitimidade cultural dos museus, proposição sociológica que explicita a classificação hierárquica de diferentes tipos de cultura. Ainda que a discussão seja antiga, datando dos anos de 1960, no nosso entender, trata-se de uma leitura datada de um de seus fundadores, Pierre Bourdieu. Se desde então temos uma discussão intensa acerca das práticas de cultura legítimas e ilegítimas, pouco se avançou (BOURDIEU, 1976, 1979; LAHIRE, 2006; DONNAT, 2003; FLEURY, 2006).

Explicando melhor, um dos protagonistas da discussão, Pierre Bourdieu, desenvolveu na França, nos anos 1960, junto com sua equipe de pesquisa, uma série de análises que revelou as diferenças nas escolhas das atividades culturais de segmentos sociais daquele país. Trabalhando com um amplo levantamento das práticas de cultura das camadas populares, médias e de elite, essas iniciativas foram capazes de introduzir no debate sociológico um caráter mais heurístico acerca do agir cotidiano. Ou seja, o modelo epistemológico posto 
em exercício por Bourdieu pôde ser reutilizado em várias formações sociais, comprovando o ideário de que as práticas culturais poderiam ser vistas ora como estratégias de distinção e ou marginalização cultural de amplos segmentos societários.

Em pesquisas realizadas, especificamente, sobre a frequência em museus na França e na Europa (BOURDIEU, 1969), observouse que ela se referia a uma prática de lazer específica de segmentos bastante escolarizados, profissionais liberais bem remunerados ou empresários de grande prestigio (BOURDIEU, 1979; BOURDIEU; DARBEL, 2003). Em síntese, a ida a museus de arte e ciências (MACMANUS, 2013) e a apreciação de obras museológicas era e é uma característica das elites culturais materialmente favorecidas. Contudo, a análise não recaiu numa leitura simplista. Contrariando o senso comum, Bourdieu acrescentou que essa particularidade cultural não derivava de uma capacidade in natura das elites. Mas ao contrário, derivava de toda um aprendizado cultural e socializador vivenciado pelos grupos, na família e na escola, algo que as permitia ao longo do tempo formatar um modelo de apreciação, construir um traquejo cognitivo e social em ambientes artísticos que os habilitavam a manejar códigos de interpretação e compreensão.

Com material estatístico farto e bem-estruturado, Bourdieu (1979) foi capaz de colocar em xeque uma máxima ainda muito em voga. Ou seja, o gosto pela arte não é um dom ou uma sensibilidade natural. Para ele e para uma série de investigadores que fizeram uso de seu instrumental teórico, as práticas de cultura são diferentemente acolhidas pelos diversos grupos devido a uma desigual divisão de recursos e privilégios de natureza social. Por exemplo, boas escolas, em que a discussão humanística na área da literatura, poesia, música e ou artes visuais fosse enfatizada ${ }^{15}$, bem como associação a uma origem social livre das exigências materiais, contribuiriam sobremaneira para o desenvolvimento de práticas de apreciação estética de uma gama variada de objetos ou bens culturais. Em outras palavras, a sensibilidade artística, o interesse ou a necessidade pela produção artística/científica não resultariam de uma capacidade inata e ou uma dádiva especial de algumas pessoas, mas teria origem nos privilégios de nascença e de escolarização que se acumulariam ao longo da vida dos indivíduos e dos grupos.

Cabe ainda um último comentário. Ao identificar a correlação entre certas práticas no grupo mais escolarizado, tais como a visitação a museus, conhecimento de música erudita ou teatro de vanguarda, Bourdieu (1979) não as associou a uma caracterização mais nobre 
ou superior a outras formas de cultura. O que ele nos legou foi uma correspondência entre essas práticas e a posse de um capital cultural, sem notadamente qualificá-las como hierarquicamente acima das outras. $\mathrm{Na}$ realidade, a distinção que os grupos mais escolarizados passam a ter a partir dessas práticas se realiza por um trabalho estratégico e arbitrário de reconversão dos capitais econômico e cultural em capital simbólico. Como Bourdieu (1979) pontuou, as vantagens e a valorização dos grupos mais bem-aquinhoados não procedem apenas da posse dos recursos financeiros e ou culturais, mas da capacidade de transformálos em objeto de poder e distinção em uma eficaz operação subjetiva, homeopática e difusa de um imaginário de superioridade.

Muito já foi discorrido sobre esse tema (BOURDIEU, 1976, 1979; LAHIRE, 2006; DONNAT, 2003; FLEURY, 2006). Todavia, o que nos interessa é que, após um momento de constrangimentos acerca dessas constatações, uma série de iniciativas por parte de curadores e pedagogos foi sendo construída na tentativa de minimizar ou diminuir as desvantagens que alguns possuíam já no início do processo de visitação a museus com ou sem programas educativos (MARANDINO, 2008; CURY, 2009; ALLARD; LANDRY, 2009).

Como verificado por estudiosos da área, os museus são pouco frequentados pela população brasileira (SETTTON, 1994, 2004, 2012). Aliás, a frequência a museus de arte e ciência seria privilégio dos segmentos mais escolarizados em quase todos os países pesquisados (BOURDIEU; DARBEL, 2003; MACMANUS, 2013; MARANDINO, 2008). Desse modo, considera-se que o discurso que retrata essas instituições como exclusivas auxilia subjetivamente e de maneira imperceptível na construção de um imaginário de que os artefatos ali em curso seriam de difícil apreensão e compreensão; um imaginário reforçado por uma série de aspectos objetivos de apresentação e construção arquitetônica dos prédios e dos acervos e de iniciativas curatoriais, tal como verificado nas duas visitas realizadas ao Museu Afro Brasil e ao MASP.

Por fim, pondera-se ainda que seria necessário reler com cuidado as considerações de Pierre Bourdieu acerca da posse de códigos de avaliação das obras culturais. Em linhas gerais, segundo ele, qualquer trabalho pedagógico, inclusive e especialmente o da escola, exige a pré-disposição a uma bagagem que permita o perfeito aproveitamento comunicativo (BOURDIEU, 1979; BOURDIEU; DARBEL, 2003). Ademais, o conhecimento prévio de um patrimônio cultural é requisito para o desfrute de qualquer prática de lazer. Filmes, TV, desenhos animados, documentários, blogs, Facebook, etc. ensejam uma 
familiaridade com a linguagem em questão. É certo que o domínio dessas linguagens demanda formações distintas. Contudo, o que os museus de arte possuem de diferente, que exige um acervo de conhecimento mais amplo e ou mais erudito do que as outras atividades culturais? Não seria um exagero imaginar que o público não teria capacidade de se sensibilizar com os artefatos museificados? Não seria demasiado elitista conceber que a arte dos museus exige mais capacidade interpretativa do que a projeção de um filme? Não estaríamos aqui reforçando subjetivamente estratégias de assimetria entre as culturas?

\section{ALGUMAS SÍNTESES}

O objetivo deste artigo foi problematizar criticamente a ideia de que os museus não estão abertos a qualquer tipo de público. Partiuse do pressuposto de que os museus, enquanto espaços educativos e socializadores, cumprem a função subliminar de transmitir, a partir de sua história e arquitetura, da apresentação de obras, seleção de acervo, entre outros aspectos, um conjunto de símbolos que prestigiam seus objetos, que, por vezes, reificam a naturez̧a sacralizada das peças de sua exposição. Para desenvolver o argumento, deu-se visibilidade ao processo de criação e manutenção do MoMA, - um dos primeiros museus com proposta educativa, cujo teor ideológico está colocado em sua fundação, bem como lembramos as iniciativas brasileiras que herdaram essa e outras propostas de matriz norte-americana. Para dar continuidade ao debate, perguntou-se sobre os programas educativos e os valores culturais ali revelados. O que se pôde resgatar foi uma história marcada por aspectos elitistas e pouco afeitos a uma ampliação de público. É notável que apenas em 1980 uma "virada educacional" evidencie esse debate. Nesse sentido, intentamos levantar explicitamente as várias tendências de aproximar ou afastar os reconhecidos "templos sagrados da cultura", os museus, para uma ampla maioria da população. Tendo apresentado as tentativas educativas organizadas e postas em prática para incentivar um desembaraço cognitivo e estético para aqueles que não tiveram essas oportunidades, foram explicitadas as estratégias objetivas e subjetivas que impedem esse avanço.

Ademais, é importante apontar que uma discussão sobre concepções de cultura educativa em museus não chega à atualidade de forma homogênea nas instituições formadoras de professores, sendo assim necessário que o tópico seja, ainda que de forma ampla, enfrentado. Paralelo a isso, alertou-se que, no senso comum, é possível verificar uma visão sobre os museus de arte, modernos ou contemporâneos, 
com uma aura de distanciamento que resulta em uma relação pouco participativa, crítica e democrática de seus gestores. Para muitos, o museu apresentaria um tipo de produção cultural que, independente da adjetivação, não é aquela compartilhada com o restante da comunidade na qual se inserem seus visitantes. É lamentável ter que lembrar que essa situação se mantém, mesmo com os esforços, desde a década de 1980, no sentido do desenvolvimento de estratégias para a aproximação e desauratização de seus acervos aos visitantes.

Vale salientar ainda que se resiste à armadilha de acreditar que uma forma de expressar a cultura seja melhor do que outras. Não se considera que a cultura culta seja um cultura superior a outras formas de cultura. Não obstante, trata-se de uma linguagem específica que pode trazer no seu interior um poder de crítica, de reflexão e/ou de desconstrução dos consensos culturais que devem e podem ser matéria da sociologia da educação. No caso dos museus de arte moderna ou contemporânea, cabe sinalizar a necessidade de uma apropriação, por parte do público, a respeito do circuito artístico, suas formas de produção e circulação, já que grande parte do que é exibido pelas instituições apresenta um tipo de reflexão altamente referenciada em produções artísticas históricas e nas maneiras pelas quais foi mostrada e compreendida.

Partindo desses pressupostos, a discussão aqui exposta evidenciou mecanismos objetivos e subjetivos que mais afastam do que aproximam determinados tipos de público da frequência aos museus. Entre esses mecanismos destaca-se o nem sempre eficiente e muitas vezes fragmentado trabalho educativo nessas instituições. Também podem contribuir um histórico marcado pela presença de especialistas e acadêmicos distantes do público não especializado, bem como um trabalho discursivo em geral elitista, construído e reproduzido inconscientemente por todos nós.

Em paralelo, observou-se, no breve histórico apresentado, que as atividades de organização das exposições em museus ainda se constituem em espaços restritos a uma camada de artistas e/ou intelectuais, que muitas vezes também auxiliam a consagrá-los como templos destinados apenas àqueles que creem predispor de códigos de apreciação. Na maioria das vezes sob a responsabilidade de agentes acadêmicos reconhecidos, de curadores e de parte da administração museológica, essa consagração vem reforçar a distância subjetiva e objetiva dos museus de um público mais amplo, pois poucos se sentem motivados pela tarefa pedagógica de democratizar os acervos. Falta de apoio e suporte financeiro acabam por consolidar essa situação. 
Ademais, verifica-se também uma forma hermética de apresentação de seus acervos, isto é, grande parte das exposições estão afastadas do contexto de sua produção, distanciando até mesmo os vocacionados da área. Incorre-se em exposições que pouco sabem das demandas de seu público, pouco explicativas e com estratégias pouco aproximativas de seu conteúdo, fatores que corroboram um distanciamento.

Em síntese, o discurso consensual desvelado por Bourdieu (1979), de que se necessita um conhecimento prévio sobre os patrimônios museológicos, bem como todo o aparato físico e pouco didático de suas exposições, nos aponta para estratégias de distanciamento ao mesmo tempo veladas e concretas, subjetivas e objetivas. Existiria aqui certa manifestação de violência simbólica (BOURDIEU, 1998), que projeta uma forma única e correta de apreciação dos artefatos artísticos/científicos. Todavia, ao contrário, julgamos que, sem a devida identificação com seu público, toda produção de cultura, esteja nos museus ou na programação televisiva, perde sua razão de ser e não se realiza enquanto projeto educacional e ou comunicativo mediador (MARTÍN-BARBERO, 1995; SETTTON, 2010; CURY, 2009).

$\mathrm{Na}$ tentativa de finalizar o argumento, reitera-se que a arte, como qualquer expressão de linguagem, é passível de interpretação e julgamento menos restritivos ou seletos. Todas elas podem se realizar como mediadoras de ampliação de uma percepção de mundo. Aliás, a arte exposta em museus, pelo simples recurso de despertar o estranhamento ou mesmo sensibilizar a capacidade estética de um público receptor, pode ser material crítico e reflexivo para todos, desde que seja acompanhado de uma abordagem aberta, provocativa e não seletiva. Ou seja, tal como o cinema ou a literatura, a visitação aos museus pode ser acompanhada de uma preocupação pedagógica anterior em que se estimulem a compreensão e/ou a interpretação variadas dos conteúdos propostos, por puro lazer e ou entretenimento (MACMANUS, 2003).

Desmistificar a aura dos objetos museificados, desnaturalizar uma única e/ou correta forma de apreciação de suas obras, são tarefas da sociologia da educação, a fim de desvelar estratégias subliminares de dominação cultural. Desqualificar o poder apreciativo de amplos segmentos da população corrobora subjetivamente na hegemonia e no domínio de um arbitrário cultural. Nesse sentido, refletir sobre isso é uma forma de se aproximar dos mecanismos objetivos e simbólicos que contribuem para o afastamento do público das obras consideradas legítimas, o que pode vir a democratizar o acesso à cultura artística.

Para concluir, além de um discurso crítico e pedagógico sobre a realidade dos museus, valeria registrar algumas etapas necessárias para 
se alcançar uma aproximação entre o público e os acervos dos museus. Mais precisamente, para colocar em prática essa intenção, não bastaria apresentar as obras e deixá-las disponíveis para visitação. Por certo, seriam necessárias ou recomendáveis iniciativas como a) as boas-vindas ao público por pessoal especializado, b) uma sinalização adequada sobre trajeto a ser percorrido na visitação ${ }^{16}$, c) mediadores com conhecimento acerca do que está sendo exposto. Esses fatores poderiam garantir um ambiente favorável a uma boa experiência educativa.

Mas o que nos parece mais difícil de se conseguir é um acordo sistemático e consensual entre os agentes desse processo educativo e sensibilizador. Para os interesses deste artigo, seria necessário pontuar um trabalho conjunto e articulado entre a) um projeto expositivo e curatorial,b) a presença e a consulta constante de educadores nos próprios museus, como equipe fixa, que, além de trazer um conhecimento sobre processos de aprendizagem, trariam ainda conhecimento do público a ser atingido. E, em se tratando de um trabalho junto com crianças, c) a visitação prévia à exposição e um trabalho de articulação de conteúdo. Nesse processo, seria fundamental um diálogo entre os professores, a equipe educativa dos museus e sua curadoria (MARANDINO, 2003; MACMANUS, 2009). Contudo, infelizmente, apenas uma política pública consistente e contínua poderia avançar nessa direção.

Nesse sentido, o artigo evidenciou a proximidade entre sociologia da cultura e sociologia da educação. Trazer para o debate o potencial educativo e emancipador da compreensão das várias linguagens sociais, entre elas as dos museus, é uma tentativa de ampliar a capacidade de autonomia cognitiva dos indivíduos em um genuíno exercício de imaginação e criação para o novo. Ademais, exercitar a dúvida sobre consensos culturais -entre eles, o consenso de que os museus exigem um conhecimento experiente sobre a arte - nos auxilia a colocar em xeque um arbitrário cultural, certa manifestação de violência simbólica, que muitos de nós ainda reforçamos. Acreditamos em um trabalho de mobilização para um saber, e esse exercício pode ter início nos cursos de Pedagogia. Apostamos que a criação de uma necessidade ou desejo cultural está presente em todos, desde que haja condições de socialização a priori.

\section{REFERÊNCIAS}

ALLARD, M.; LANDRY, A. O estado da arte da pesquisa sobre educação museal no Canadá. In: MARANDINO, M.; ALMEIDA, A.; VALENTE, M. Museu, lugar do público. Rio de Janeiro: Fiocruz, 2009. p. 30-40.

BARBOSA, A. M. A imagem no ensino da arte: anos 1980 e novos tempos. 7. ed. rev. São Paulo: Perspectiva, 2009. 
BARBOSA, A. M.; SALES, H. M. (Org.). O ensino da arte e sua história. In: SIMPÓSIO INTERNACIONAL, 3, 1990, São Paulo. Anais do Simpósio Internacional Ensino da Arte e sua História. São Paulo: MAC, USP, 1990. p. 30-40.

BIRKETT, W. B. To infinity and beyond: A critique of the aesthetic white cube. 2012. 87 pages. Master of Art in Museum Professions, Seton Hall University, South Orange, NJ, 2012. BOURDIEU, P. L'amour de l'art, les musées d'art européens et leur public. Paris: Minuit, 1969.

BOURDIEU, P. Anatomy du Goût. In: BOURDIEU, Pierre. Actes de la Recherche em Sciences Sociales. Paris, 1976. p. 2-43.

BOURDIEU, P. La distinction: critique social du jugement. Paris: Minuit, 1979.

BOURDIEU, P. O poder simbólico. Portugal: Bertrand, 1998.

BOURDIEU, P.; DARBEL, A. O amor pela arte: os museus de arte na Europa e seu público. São Paulo: Zouk, 2003.

CURY, Marilia Xavier. Uma perspectiva teórica e metodológica para a pesquisa de recepção em museus. In: MARANDINO, M.; ALMEIDA, A.; VALENTE, M. Museu, lugar do público. Rio de Janeiro: Fiocruz, 2009. p. 33-50.

DONNAT, Olivier. Regards croisés sur les pratiques culturelles. Paris: La Documentation Française, 2003.

ESTADO DE SÃO PAULO. São Paulo, 24. nov. 2014. Economia e Negócios, p. A17.

FLEURY, Laurent. Sociologie de la cultura et des pratiques culturelles. Paris: Armand Colin, 2006.

HUNTER, Sam. The Museum of Modern Art New York: the history and the collection. New York: Abradele Press/H.N. Abrams in association with the Museus of Modern Art, 1997.

LAHIRE, Bernard. A cultura dos indivíduos. Porto Alegre: Artmed, 2006.

MACMANUS, Paulette. Educação em museus: pesquisa e prática. In: MARANDINO, M.; MONACO, L. (Org.). Educação em Museus: pesquisas e prática. São Paulo: Faculdade de Educação, USP, 2013. p. 20-30.

MARANDINO, Marta. Educação em museus: a mediação em foco. São Paulo: FE-USP, 2008.

MARTÍN-BARBERO, Jesús. Dos meios às mediações. Comunicação, cultura e hegemonia. Rio de Janeiro: UFRJ, 1995.

MÖRSCH, Carmen. Educación crítica en museos y exposiciones en el contexto del "giro educativo" en el discurso comisarial: ambigüedades, contradicciones y alianzas. 2011. Disponível em: <http://www.mde11.org/wordpress/wpcontent/uploads/2011/09/ Educaci $\% \mathrm{C} 3 \% \mathrm{~B} 3 \mathrm{n}-\mathrm{cr} \% \mathrm{C} 3 \%$ ADtica-en-museos-y-exposiciones...-Carmen-Morsch.pdf $>$. Acesso em: 10 jun. 2015.

OLIVEIRA, M.C.M. História como estratégia: uma apropriação da Abordagem triangular para uma educação não conformista. In: BARBOSA, A.M.; CUNHA, F. (Org.) Abordagem triangular: no ensino das artes e culturas visuais. São Paulo: Cortêz, 2010.

O’NEILL, Paul; WILSON, Mick (Ed.). Curating and Educational Turn. London: Open Editions; Amsterdam: De Appel Arts Centre, 2010.

ROSSETTI, Eduardo Pierrotti. Tensão moderno/popular em Lina Bo Bardi: nexos de arquitetura. Arquitextos, 032.06, v. 3, jan. 2003. Disponível em: <http://www.vitruvius. com.br/revistas/read/arquitextos/03.032/717>. Acesso em: 10 jun. 2015.

SABOR, Dora L. de C. A fotografia no Ensino Fundamental de uma escola pública. Número 5. 2014. Dissertação (Mestrado em Design) - Universidade Anhembi, Morumbi, São Paulo, 2014. 
SETTON, Maria da Graça J. Professor variações sobre um gosto de classe. Educação e Sociedade, ano XV- abr/1994, p. 73-96.

SETTON, Maria da Graça J. Rotary Club: habitus, estilo de vida e sociabilidade. São Paulo: Annablume, 2004.

SETTTON, Maria da Graça J. Mídia e Educação. São Paulo: Contexto. 2010.

SETTON, Maria da Graça J. Socialização e Cultura: ensaios teóricos. São Paulo, Editora Annablume, 2012.

STANISZEWSKI, Mary-Anne. The power of display: a history of exhibitions installations at the Museum of Modern Art. Cambridge, Massachusetts/London, England: MIT Press, 1998.

TOTA, Antonio Pedro. O amigo americano: Nelson Rockefeller e o Brasil. São Paulo: Companhia das Letras, 2014.

\section{NOTAS}

${ }^{1}$ O Museu Afro Brasil fundado por ocasião do aniversário de 500 anos do Brasil, desde seu início, tem sido administrado por um de seus incentivadores, o artista e curador Emanoel Araújo. A maior parte do acervo pertence ou foi doado à instituição por ele. Localizado no Pavilhão Manuel da Nóbrega, no Parque do Ibirapuera, em São Paulo, conserva um dos maiores testemunhos da história, da tradição e da arte negra no Brasil.

${ }^{2}$ Segundo Macmanus (2013), os museus não são espaços apenas de conservar objetos, mas são lugares em que se misturam várias linguagens e em que se tem o compromisso de difundir cultura. Nesse sentido, devem se aproximar de todas as outras formas de comunicação, sejam elas de ordem imagética ou sonora. "O importante é entender o museu como local onde o curador coleta os objetos, o conservador conserva aqueles objetos e tudo isso será exposto e, portanto, o museu e a exposição têm de ser vistos como uma mídia. Como a televisão é uma mídia, uma exposição e o museu também são" (MACMANUS, 2013, p. 24).

${ }^{3}$ Os autores apontam, a partir da exposição de vários depoimentos, a crescente preocupação da curadoria e dos artistas no desenvolvimento de práticas e incorporação de um vocabulário do campo educacional. Dessa forma, são frequentes a apresentação de seminários; a indicação de que obras e curadoria resultam de pesquisas ou na solicitação de ações participativas por parte do visitante, entre outras propostas.

${ }^{4}$ A noção de curadoria no campo artístico, tal como compreendida nos dias de hoje, foi elaborada recentemente, a partir dos anos de 1960. Até então, a organização das exposições era atribuição dos diretores e dos conservadores dos museus, sempre de uma perspectiva institucional. Aquelas exposições que aconteciam fora desse circuito - em galerias comerciais ou espaços adaptados - eram organizadas pelos galeristas ou por artistas. A geração dos anos de 1960 que inaugura essa nova modalidade profissional, o curador independente, cuja função comporta uma perspectiva crítica e autoral, é formada por um pequeno grupo: Harald Szeemann, Lucy Lippard, Seth Siegelaub, Kynaston McShine, Marcia Tucker, entre outros.

${ }^{5}$ Sob nova direção. Com doação média de R\$ 100 mil, grupo de empresários e altos executivos angariou R $\$ 15$ milhões, em uma das maiores captações já feitas para um museu privado; objetivo era quitar dívidas antigas e dar fôlego à nova administração da instituição (ESTADO DE SÃO PAULO, 2014).

${ }^{6}$ Para um aprofundado contato com as múltiplas e estratégicas formas de atuação de Rockfeller na América Latina e em especial sua influência no Brasil, ver TOTA, 2014.

${ }^{7}$ Machine Art foi organizada pelo MoMA em 1934, com curadoria de Philip Johnson, mas não foi a única mostra em sintonia com os produtos da sociedade de consumo norte-americana. 
Para detalhes das atividades do MoMA desde sua fundação, ver o aprofundado estudo de Staniszewski (1998).

${ }^{8}$ O MASP antes de se fixar na Avenida Paulista ocupou o prédio dos Diários Associados, na Rua Sete de Abril, e o prédio da Fundação Armando Álvares Penteado (FAAP). Lembra-se aqui que até 2014 o MASP não possuía nem uma peça de arte indígena nem mesmo popular, o que tem sido debatido em 2016 no âmbito das ações do próprio Museu (ESTADO DE SÃO PAULO, 2014).

${ }^{9}$ Acerca do envolvimento educativo de Lina Bo Bardi em relação às suas premissas arquitetônicas e museais, consultar Rossetti (2003).

${ }^{10}$ Numa tentativa de resgatar essa missão, o MASP promove um conjunto de palestras para junho de 2015. Maiores detalhes no endereço: <http://masp.art.br/masp2010/ servicoeducativo_seminario-de-educacao.php>.

${ }^{11}$ Selecionamos cinco museus que possuem acervos e propostas semelhantes, tais como: MASP, MAM-SP, MAC-USP, Pinacoteca do Estado e Museu Afro Brasil.

${ }^{12}$ Como exemplo, as diversas reimpressões e reedições de $A$ Imagem no Ensino da Arte trazem comentários de Barbosa, revisando os próprios conceitos e respondendo críticas à sua elaboração. Abordagem Triangular no Ensino das Artes e Culturas Visuais, lançado em 2010, buscou realizar uma revisão da abordagem e um mapeamento das formas pelas quais essa teoria foi lida e praticada.

${ }^{13}$ Dados os limites desse artigo, não será possível desenvolver outras iniciativas educativas tais como as das Bienais e do Projeto Arte na Escola da Fundação Iochpe. Todavia, vale salientar que todas elas tiveram sucesso restrito e foram elaboradas e desenvolvidas em diálogo com as propostas de Barbosa. O setor educativo da Bienal consolidou-se desde a 29a edição do evento, em 2010, com a criação de um departamento fixo. Vale lembrar que na presente década o que se denominou virada educacional na curadoria passa a evidenciar outra proposta de relação instituição/obra/visitante. Para esse tópico, consultar as publicações da artista e educadora Graziela Kunsch no endereço: http://www.naocaber.org/wp-content/uploads/2015/01/urbania5_web_pags-juntas.pdf.

${ }^{14}$ Foram coletadas informações disponíveis nos websites dos museus, portanto a amostragem não é exaustiva ou sistematizada, já que cada instituição fornece a partir suas contingências. Foram escolhidos para a amostragem museus de arte que apresentam obras modernas e contemporâneas, ainda que suas coleções não se limitem à esse foco. Desses, foram pinçadas aquelas instituições cuja localização central na cidade de São Paulo permitam fácil acesso, de modo a acolher a visitação espontânea ou planejada.

${ }^{15}$ A realidade educacional de alguns Centro Unificados de Educação (CEU) paulistas podem servir de exemplos.

${ }^{16}$ As propostas mais contemporâneas nem sempre se outorgam essa tarefa, já que parte do que o visitante pode construir em termos de conhecimento - principalmente de arte - também inclui uma elaboração de percurso próprio, ou pelo menos a desconstrução de narrativas impostas.

Submetido: 17/04/2016

Aprovado: 01/11/2016

Contato:

Cidade Universitária

Avenida da Universidade, 308, Butantã

São Paulo $|\mathrm{SP}|$ Brasil

CEP: 05508-040 